\title{
The Logic of Microaggressions Assumes a Racist Society $\mathrm{X}(\mathrm{X}), \mathrm{XX}-\mathrm{XX}$ \\ (C) The Author(s) 2021 \\ Not the version of record. \\ The version of record is available at DOI: $X X X X X X X X$ \\ journals.sagepub.com/home/pps
}

Perspectives on Psychological Science,

\section{Moin Syed'}

\begin{abstract}
This commentary draws attention to core assumptions about the nature of society that underlie the current debate on microaggressions. For proponents of microaggressions research, the starting assumption is one of a racist society. That is, microaggressions have their source and power within an inequitable, racially-stratified society. In contrast, critics of microaggressions begin with the assumption of an equitable society, or at least would not endorse the assumption of a racist society. These two different starting assumptions lead to drastically different conclusions about the concept of microaggressions. So long as these assumptions are not explicitly recognized, debates on methods, findings, and so on will never be reconciled.
\end{abstract}

\section{Keywords}

microaggressions, racism, passive racism, systemic racism, assumptions, models

'Department of Psychology, University of Minnesota, Minneapolis, MN, USA

\section{Corresponding Author:}

Moin Syed, moin@umn.edu

Note. This document was typeset using Wiernik's (2019) \#prettypreprint template.

This article has been accepted for publication in Perspectives on Psychological Science. Version date 01/04/2I. This is not the final version of record. I am grateful for helpful comments from Alex Ajayi and jill Fish on a previous version of this commentary. This essay is no. 12 in the series, "I Got a Lot of Problems with Psychology." 
The concept of microaggressions has been heavily criticized and debated in recent years. Whereas controversy and disagreement over concepts and methods has existed since microaggressions entered mainstream psychology ${ }^{1}$ and popular culture (Sue et al., 2007, see commentaries by Harris, 2009; Schacht, 2008; Thomas, 2008), the situation hit a fever pitch with Lilienfeld's (2017) detailed critique and subsequent responses (e.g., Kraus \& Park, 2017). Most recently, Williams (2020a, 2020b) and Lilienfeld (2020) engaged in a lengthy back-and-forth concerning concepts and evidence, reaching little agreement on some of the core debates.

The debate about microaggressions has included empirical (Lui \& Quezada, 2019; Ong \& Burrow, 2017; West, 2019; Williams, in press), analytic (McClure \& Rini, 2020), and ideological responses (Haidt, 2017; Sue, 2017). Throughout it all, this seemingly intractable debate has largely focused on issues such as construct definition, measurement, interpersonal dynamics, and impacts on mental health - all critical issues that need to be discussed within a healthy science of psychology. But at the same time, these are the issues that psychologists tend to focus on at the expense of others. In this brief commentary, I draw attention to how much of the debate about microaggressions is rooted in differing starting assumptions about the nature of society - a level of analysis that psychologists tend not to focus on as heavily.

In particular, the debate about microaggressions reflects differing assumptions about the nature and role of race and racism ${ }^{2}$ in U.S. society ${ }^{3}$. On the one hand, proponents of the utility of microaggressions research start from the assumption that society is racist, and that microaggressions are behaviors that must be understood in that context (cf. Kraus \& Park, 2017). On the other hand, critics of microaggressions assume racism to be an interpersonal act not linked to broader systems of power and privilege (e.g., Schacht, 2008). These opposing views are by no means limited to the context of microaggressions, but rather reflect broader differences in views on race and racism in U.S. society (see, for example, the debate about the "dictionary definition" of racism in McWhorter, 2020). Indeed, the distinction between systemic and interpersonal racial frameworks has broad implications, and is at the heart of many disagreements about the past, present, and future of race relations in the U.S., and thus this commentary in intended to draw attention to how these assumptive framework underlie many different contemporary arguments. As I explain further below, this difference in foundational assumptions underlies some of the core contemporary debates in the field. Whereas my intention is to advance our understanding of microaggressions specifically, this commentary also represents a broader call for psychologists to attend much more closely to the assumptions that underlie their research and scholarly views (see Slife et al., 2005).

As is clear from papers by Williams (2020a, 2020b) and other microaggressions researchers (Solórzano, 1998; Sue et al., 2007), the starting assumption is one of a racist society. Indeed, a great deal of research and theorizing on microaggressions that occurred between Pierce (1970) and Sue et al., (2007) was situated within Critical Race Theory, a framework that takes an explicitly structural view to understand the causes and consequences of racism (Solórzano et al., 2000; Solórzano et al., 2002). From this perspective, microaggressions have their source and power within an inequitable, racially-stratified society. This is an assumption within microaggressions research because it is never tested empirically and rarely even directly stated, and in effect serves as a conceptual framework through which race and racism can be understood (Kraus \& Park, 2017). To be sure, much of what is discussed in this commentary is fully evident in Williams (2020a). What I am doing here is explicitly calling out the underlying framework to contrast it with the alternative.

Claiming that society is racist is not only a statement about the nature of society, but provides a framework for understanding individual behavioral responses, which I will refer to as the systemic racial framework. As described by Tatum (1997), individuals living in a racist society have one of three positions they can take: 1) accept the racist society and be actively racist by engaging in intentional, overt acts of racism. This response corresponds to what is often referred to as blatant or old-fashioned racism;2) acknowledge 
the racist society and be actively anti-racist, by using accessible forms of privilege to dismantle the racist system; and 3) to be largely ignorant of societal racism, or to acknowledge racism as an individual behavior vs. a system. This leads to passive racism, because if individuals live in a racist society, and do nothing to counter that racism, they will engage in behaviors that maintain the racial system. Importantly, these responses are not meant to be typologies of individuals but rather describe behavioral responses, and thus individuals can engage in all three responses at different times and in different situations.

This model of individual responses within a racist society underlies all theory and research on microaggressions and helps clarify some of the confusions and debates in the literature (cf. McClure \& Rini, 2020). Within this framework, microaggressions are not viewed as purely individual, interpersonal acts, nor are they solely systemic forces. Rather individuals mediate societal racism within interpersonal situations (Huber \& Solorzano, 2014).
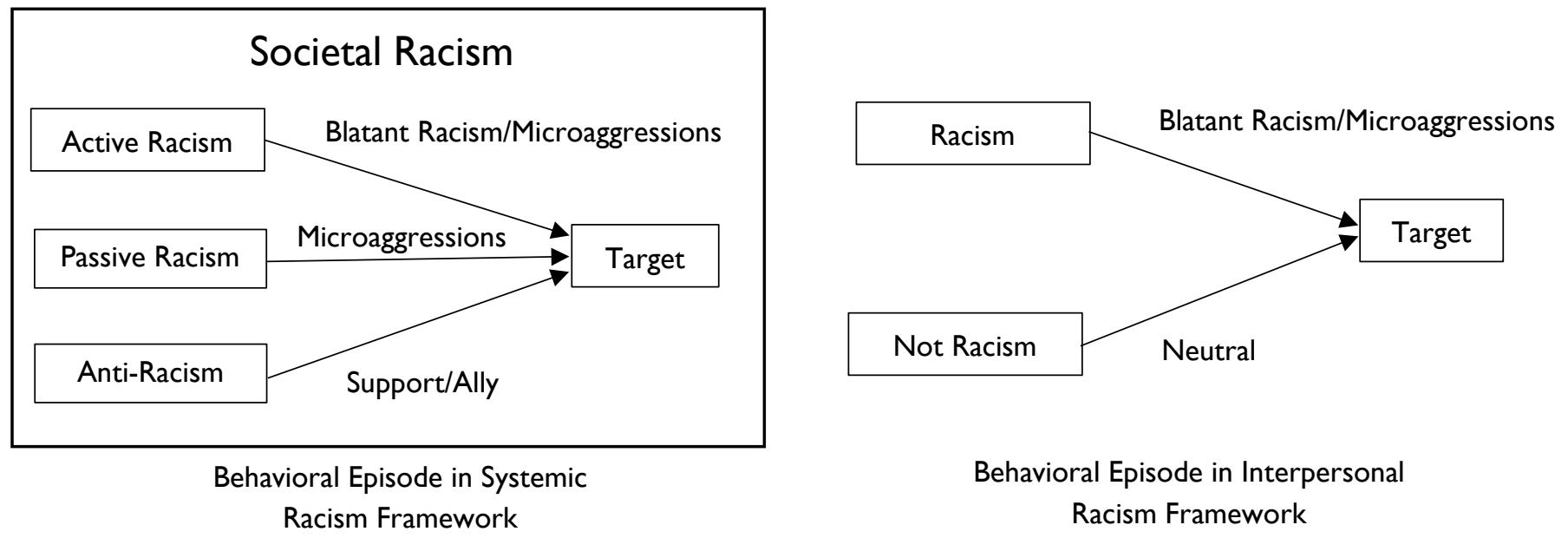

Behavioral Episode in Interpersonal Racism Framework

Figure 1. Schematic representations of racism in systemic (left) and interpersonal (right) frameworks. In the systemic framework, active racism involves engagement in either blatant racism or microaggressions, depending on the type; passive racism primarily aligns with microaggressions; and anti-racism involves behavior that is in active support or in allyship with those targeted by racism. In the interpersonal framework, racism is the root of all blatant racism and microaggressions, and those not engaging in racism behave in a neutral way towards targets, which can have both positive and negative impacts.

An alternative underlying assumption for understanding racism and microaggressions is that they are products of individual beliefs and thus are best understood as interpersonal acts (Schacht, 2008; Thomas, 2008). I will refer to this as the interpersonal racial framework. This assumption is clearly evident in the critiques by Lilienfeld (2017a, 2017b, 2020). Such an assumption may be paired with a belief in an equitable, just society (Kraus \& Park, 2017), although those endorsing this assumption might also agree that society is racist, or at least that racism exists at a societal level in some situations. However, the assumption with respect to microaggressions is not that the individual behavior is mediating societal structures. Rather, individual behavior is understood as an interaction between dispositional and situational factors.

As illustrated in Figure 1, these two frameworks differentially locate the source of microaggressions. From a systemic framework, microaggressions can represent both active and passive racist responses, depending on the type. For example, the conscious and intentional forms, what Sue et al. (2007) called "microassaults" are likely a product of active racism. However, the majority of microaggressions, and really the heart of the concept, are a product of passive racism. Indeed, Williams (2020a) stated that, "Microaggressions are by definition caused by socially conditioned racial biases and prejudices," (p. 6) and 
"Microaggressions are invisible to many White people because they are socialized not to see racial inequities" (p. 8). Reading between the lines, both of these statements highlight how microaggressions are largely a manifestation of passive racism. If individuals are not aware of, or are in denial about, the racist nature of society, then they will also have little awareness of how their seemingly innocuous behaviors can be interpreted as racist.

In contrast, because the interpersonal framework does not make a distinction between active and passive racism, microaggressions are only understood as manifestations of active racism. Indeed, Lilienfeld (2020) stated:

Williams's definition of microaggressions as "deniable acts of racism" (p. 4) declares microaggressions to be inherently racist by fiat, thereby placing the critical question of whether microaggressions are statistically associated with racist tendencies (e.g., Kanter et al., 2017) outside the scope of scientific inquiry (p. 28).

This quote nicely encapsulates the different assumptions. Lilienfeld has maintained that it is a problem for microaggressions research that their enactment is not strongly associated with other manifestations of racism. This view assumes that microaggressions only represent active racism. If they represent both active and passive racism, and predominantly the latter, then trivial-to-small associations with other racist tendencies would be expected. Moreover, the question of associations among constructs is not "outside the scope of scientific inquiry," but rather not as simple and straight-forward as portrayed—but only depending on which framework for racism one assumes.

The above Lilienfeld quote continues, "Williams's definition further precludes the possibility that certain microaggressions reflect misstatements or misunderstandings of cultural norms" (p. 28). Indeed, the question of "intent" has loomed large in the debate on microaggressions, being identified as of central importance among critics (Haidt, 2017; Lilienfeld, 2017a; Thomas, 2008) and mostly irrelevant among defenders (Kraus \& Park, 2017; Sue et al., 2009; Williams, 2020a). As alluded to above, intent will vary depending on the type of response in question. Microaggressions rooted in active racism are more likely to be intentional, whereas those rooted in passive racism are more likely to be unintentional. Again, the interpersonal framework makes no distinction between active and passive racism, and therefore any act of racism must be intentional and reflect something about the perpetrator's character. To be clear, it is not the case that character is irrelevant. Williams (in press) recently found consistent associations among White Americans' willingness to engage in microaggressions and several measures of aggressive tendencies. However, the study did not make an empirical distinction between microaggressions due to actively racist and passively racist sources.

Lilienfeld has also argued for the need to "assess microaggressions within a multi-informant approach that incorporates self and observer reports" (2017b, p. 179). In contrast, microaggressions researchers have maintained that the view of the perceiver/target should be prioritized and that it is unlikely that the perpetrators' view will align with those of the target (Kraus \& Park, 2017; see McClure \& Rini, 2020 for a detailed account of these views). This disagreement can, again, be understood as rooted in the different racial frameworks. From the systemic view, active racist behavior may be reliably identified by observers, but passive racism via microaggressions may not be. Part of the reason for this is that any single instance of a microaggression may seem totally innocuous to an outside observer (Thomas, 2008), but the repeated instances of the behavior - known only to the target - are what can make the singular experience stressful.

This phenomenon can be illustrated through a personal experience: On an at least weekly basis, for my entire life, when introducing myself to others I get a response of "well that is an interesting/unusual name" or "I have never heard that before" or "what kind of name is that?" From the interpersonal framework such 
questions would be seen as rooted in curiosity, interest, and perhaps even friendliness on the part of the questioner. An outside observer may agree that there is nothing racist about those questions. However, if you take seriously my reporting of hearing this question weekly for my whole life, that means I have been subject to that question 2,184 times $^{4}$. It impacts my stress and behavior because I know the question is coming and will choose to not introduce myself to new people in order to avoid it.

I offer my personal experience not as evidence or proof of any particular point other than to highlight that the question of corroboration of microaggressions is no simple matter of gathering observer reports. Any observer would have no access to the accumulation of my experiences or to my internal reactions to the situation (See Lui et al., 2020). It is common in the debate on microaggressions to focus on the interpretation of a singular event and whether or not it constitutes racism (e.g., Harris, 2008; McClure \& Rini, 2020). Conceptually, a singular experience of a microaggression should not have any impact on the target; it is the cumulative experience of them that can be detrimental. Again, none of this is not to say that we should not seek to better understand how these experiences might be observable to others, but rather that doing so would require a proper acknowledgement of the phenomenon.

\section{So Where to From Here?}

The purpose of this commentary is to surface assumptions that underlie the ongoing debate about microaggressions. So long as these assumptions are not explicitly recognized, debates on methods, findings, and so on will never be reconciled. Endorsement of the systemic and interpersonal frameworks remain as assumptions because they cannot be directly subject to empirical test. Moreover, these are not only assumptions researchers have about microaggressions, but assumptions they have about the world itself. Historically in the U.S. individuals - especially those who are White - have been socialized to adopt an equality-based, colorblind, individual-focused worldview, and not one that draws attention systemic forces (Abaied \& Perry, 2020; Bonilla-Silva, 2015). In contrast, socialization around the systemic view is much more common among ethnic/racial minorities (Hughes et al., 2006; Loyd \& Gaither, 2018). Of course our own socialization and beliefs play a role in how we understand this debate.

As scientists, however, we must examine the available evidence in support of the different frameworks and come to conclusions about which assumption is more plausible given the evidence. Whereas my intention is to not adjudicate between the systemic and interpersonal frameworks, it should be clear to even mildly attentive readers that I favor the systemic framework. I come to this conclusion in a scientific context not via personal belief ${ }^{5}$, but rather because the accumulated evidence points strongly in that direction. Compelling evidence for the systemic framework has been provided by numerous scholars (Bonilla-Silva, 2015; Brave Heart et al., 2011; Lipsitz, 2006; Roberts \& Rizzo, 2020). Very few would deny that the U.S. has historically been a racist society, given its history of slavery, colonization, dehumanization, and restriction of basic rights and freedoms for its ethnic/racial minority populations. Thus, the question is, when exactly in history did the U.S. stop being a racist society?

The above argument aside, which framework researchers should adopt and the preponderance of evidence is not the point of this commentary. The point is that these assumptive frameworks are lurking in the debate about microaggressions, and if we do not surface them during the debate then we are doomed to make little progress. And, to be clear, progress needs to be made. Defensive responses such as those provided by Sue (2017) do little to move our scientific knowledge forward. Although there have been many mistaken assumptions and misunderstandings about the state of the literature, Lilienfeld (2017a) and others have made insightful and useful critiques that microaggressions researchers should take seriously, so long as they — and the critics — do so whilst being mindful of their assumptions. 


\section{Footnotes}

${ }^{1}$ Yes, I am aware that the concept of microaggression goes back to Pierce (1970), but it is inarguably the case that the Sue at al. (2007) article brought the concept to the mainstream.

${ }^{2}$ Microaggressions are not limited to race, but that has been the primary topic of research and debate, so that is the focus of the discussion.

${ }^{3}$ The overwhelming majority of research on microaggression has been conducted in the U.S., so this commentary is limited to that context.

${ }^{4}$ This may seem like hyperbole, but if anything it is likely an underestimate, as the frequency of this experience was greatly heightened during educational and residential transitions. And sure, if you feel compelled, subtract 156 instances to account for my first three years of life when the question was likely directed at my parents, not me.

${ }_{5}$ Although yes, I also personally believe this to be the case.

\section{Declaration of Conflicting Interests}

The author(s) declared no potential conflicts of interest with respect to the research, authorship, and/or publication of this article.

\section{Funding}

The authors received no financial support for the research, authorship, and/or publication of this article.

\section{ORCID iD}

Moin Syed (iD https://orcid.org/0000-0003-4759-3555

\section{References}

Abaied, J. L., \& Perry, S. (2020). Socialization of Racial Ideology by White Parents. PsyArXiv. https://doi.org/10.31234/osf.io/yr8aw

Bonilla-Silva, E. (2015). The Structure of Racism in Color-Blind, "Post-Racial" America. American Behavioral Scientist, 59(11), 1358-1376. https://doi.org/10.1177/0002764215586826

Brave Heart, M. Y. H., Chase, J., Elkins, J., \& Altschul, D. B. (2011). Historical Trauma Among Indigenous Peoples of the Americas: Concepts, Research, and Clinical Considerations. Journal of Psychoactive Drugs, 43(4), 282-290. https://doi.org/10.1080/02791072.2011.628913

Slife, B. D., Reber, J. S., \& Richardson, F. C. (2005). Critical thinking about psychology: Hidden assumptions and plausible alternatives. American Psychological Association.

Haidt, J. (2017). The Unwisest Idea on Campus: Commentary on Lilienfeld (2017). Perspectives on Psychological Science, 12(1), 176-177. https://doi.org/10.1177/1745691616667050

Huber, L. P., \& Solorzano, D. G. (2015). Racial microaggressions as a tool for critical race research. Race Ethnicity and Education, 18, 297-320.

Hughes, D., Rodriguez, J., Smith, E. P., Johnson, D. J., Stevenson, H. C., \& Spicer, P. (2006). Parents' ethnic-racial socialization practices: A review of research and directions for future study. Developmental Psychology, 42(5), 747-770. https://doi.org/10.1037/0012-1649.42.5.747

Kraus, M. W., \& Park, J. W. (2017). Microaggressions as part of the historical context of stigma and prejudice. PsyArXiv. https://doi.org/10.31234/osf.io/622ke

Lilienfeld, S. O. (2017a). Microaggressions: Strong Claims, Inadequate Evidence. Perspectives on Psychological Science, 12(1), 138-169. https://doi.org/10.1177/1745691616659391

Lilienfeld, S. O. (2017b). Through a Glass, Darkly: Microaggressions and Psychological Science. Perspectives on Psychological Science, 12(1), 178-180. https://doi.org/10.1177/1745691616669098

Lilienfeld, S. O. (2020). Microaggression Research and Application: Clarifications, Corrections, and Common Ground. Perspectives on Psychological Science, 15(1), 27-37. https://doi.org/10.1177/1745691619867117

Lipsitz, G. (2006). The possessive investment in Whiteness: How white people profit from identity politics. Temple University Press.

Loyd, A. B., \& Gaither, S. E. (2018). Racial/ethnic socialization for White youth: What we know and future directions. Journal of Applied Developmental Psychology, 59, 54-64. https://doi.org/10.1016/j.appdev.2018.05.004

Lui, P. P., Berkley, S. R., Pham, S., \& Sanders, L. (2020). Is microaggression an oxymoron? A mixed methods study on attitudes toward racial microaggressions among United States university students. PLOS ONE, 15(12), e0243058. https://doi.org/10.1371/journal.pone.0243058 
Lui, P. P., \& Quezada, L. (2019). Associations Between Microaggression and Adjustment Outcomes: A Meta-Analytic and Narrative Review. Psychological Bulletin, 145(1), 45-78.

McClure, E., \& Rini, R. (2020). Microaggression: Conceptual and scientific issues. Philosophy Compass, $15(4)$, e12659. https://doi.org/10.1111/phc3.12659

McWhorter, J. (2020, June 22). The Dictionary Definition of "Racism" Has to Change. The Atlantic. https://www.theatlantic.com/ideas/archive/2020/06/dictionary-definition-racism-has-change/613324/

Ong, A. D., \& Burrow, A. L. (2017). Microaggressions and Daily Experience: Depicting Life as It Is Lived. Perspectives on Psychological Science, 12(1), 173-175. https://doi.org/10.1177/1745691616664505

Pierce, C. (1970). Offenisve mechanisms. In F. B. Barbour (Ed.), The Black seventies (pp. 265-282). Porter Sargent.

Roberts, S. O., \& Rizzo, M. T. (2020). The psychology of American racism. American Psychologist. https://doi.org/10.1037/amp0000642

Schacht, T. E. (2008). A broader view of racial microaggression in psychotherapy. American Psychologist, 63(4), $273-273$. https://doi.org/10.1037/0003-066X.63.4.273

Solórzano, D. G. (1998). Critical race theory, race and gender microaggressions, and the experience of Chicana and Chicano scholars. International Journal of Qualitative Studies in Education, 11(1), 121-136. https://doi.org/10.1080/095183998236926

Solórzano, D., Carroll, G., Ceja, M., Dinwiddie, G., Guillory, E., \& Gonzalez, G. (2002). Keeping race in place: Racial microaggressions and campus racial climate at the University of California, Berkeley. Chicano-Latino Law Review, 23, 15-112.

Solórzano, D., Ceja, M., \& Yosso, T. (2000). Critical Race Theory, Racial Microaggressions, and Campus Racial Climate: The Experiences of African American College Students. The Journal of Negro Education, 69(1/2), 60-73.

Sue, D. W. (2017). Microaggressions and "Evidence": Empirical or Experiential Reality? Perspectives on Psychological Science, 12(1), 170-172. https://doi.org/10.1177/1745691616664437

Sue, D. W., Capodilupo, C. M., Nadal, K. L., \& Torino, G. C. (2008). Racial microaggressions and the power to define reality. American Psychologist, 63(4), 277-279. https://doi.org/10.1037/0003-066X.63.4.277

Sue, D. W., Capodilupo, C. M., Torino, G. C., Bucceri, J. M., Holder, A. M. B., Nadal, K. L., \& Esquilin, M. (2007). Racial microaggressions in everyday life: Implications for clinical practice. American Psychologist, 62(4), 271-286. https://doi.org/10.1037/0003-066X.62.4.271

Tatum, B. D. (1997). "Why are all the Black kids sitting together in the cafeteria?" and other conversations about race. BasicBooks.

Thomas, K. R. (2008). Macrononsense in multiculturalism. American Psychologist, 63(4), 274-275. https://doi.org/10.1037/0003-066X.63.4.274

West, K. (2019). Testing Hypersensitive Responses: Ethnic Minorities Are Not More Sensitive to Microaggressions, They Just Experience Them More Frequently. Personality and Social Psychology Bulletin, 45(11), 1619-1632. https://doi.org/10.1177/0146167219838790

Wiernik, B. M. (2019, October 11). Preprint templates. https://doi.org/10.17605/OSF.IO/HSV6A

Williams, M. T. (in press). Microaggressions are a form of aggression. Behavior Therapy. doi: 10.1016/j.beth.2020.09.001

Williams, M. T. (2020a). Microaggressions: Clarification, Evidence, and Impact. Perspectives on Psychological Science, 15(1), 3-26. https://doi.org/10.1177/1745691619827499

Williams, M. T. (2020b). Psychology Cannot Afford to Ignore the Many Harms Caused by Microaggressions. Perspectives on Psychological Science, 15(1), 38-43. https://doi.org/10.1177/1745691619893362

\section{Author Biography}

Moin Syed is an Associate Professor of Psychology at the University of Minnesota. His research is broadly concerned with identity and personality development among ethnically and culturally-diverse adolescents and emerging adults. He is currently the Editor of Infant and Child Development, is co-Editor (with Kate C. McLean) of the Oxford Handbook of Identity Development, the past Editor of Emerging Adulthood, the official journal of the Society for the Study of Emerging Adulthood, and is past President of the International Society for Research on Identity. 